\title{
ANÁLISE DE RESTRIÇÃO DE DNA RIBOSSOMAL AMPLIFICADO (ARDRA) PODE DIFERENCIAR Fusarium solani f. sp. phaseoli DE F. solani f. sp. glycines
}

\author{
VIRGÍNIA C. de OLIVEIRA* \& JEFFERSON L. S. da COSTA* \\ Embrapa Tabuleiros Costeiros, Cx. Postal 44, CEP 49001-970, Aracaju, SE, fax: (079) 226-1369, \\ e-mail: jcosta@cpatc.embrapa.br
}

(Aceito para publicação em 20/08/2002)

Autor para correspondência: Jefferson Luis da Silva Costa

OLIVEIRA, V.C. de \& COSTA, J.L.da S. Análise de restrição de DNA ribossomal amplificado (ARDRA) pode diferenciar Fusarium solani f. sp. phaseoli de F. solani f. sp. glycines. Fitopatologia Brasileira 27:631-634. 2002.

\section{RESUMO}

Métodos moleculares têm sido utilizados para caracterizar a diversidade entre isolados de Fusarium spp. patogênicos e não patogênicos a uma cultura e, para determinar relações genéticas entre formae speciales. Testes de patogenicidade realizados em soja (Glycine max) e feijoeiro (Phaseolus vulgaris) com 17 isolados de Fusarium solani não demonstraram especificidade de hospedeiros. Utilizou-se a técnica ARDRA (Amplified Ribosomal DNA Restriction Analysis) para analisar a região ITS1 - 5,8S rDNA - ITS2, amplificada com os primers ITS5 e ITS4. Os produtos amplificados foram digeridos com as enzimas de restrição Hae III e Msp I. Os padrões de bandas gerados pela digestão com a enzima Hae III permitiram diferenciar três grupos entre os isolados de $F$. solani, sendo um grupo específico para isolados de F. solani f. sp. phaseoli com $100 \%$ de similaridade entre os 11 isolados. Entre os isolados de F. solani f. sp glycines foram observados dois padrões distintos de restrição. A técnica de ARDRA utilizando a enzima Hae III apresenta, portanto, potencial para utilização como um marcador para diferenciação entre as formae speciales phaseoli $e$ glycines, dentro do complexo $F$. solani.

Palavras-chave adicionais: formae specialis, Phaseolus vulgaris, Glycine max.

\section{ABSTRACT \\ Restriction analysis of rDNA (ARDRA) can differentiate Fusarium solani f. sp. phaseoli from $F$. solani f. sp. glycines}

Molecular methods have been used to characterize diversity among pathogenic and non pathogenic isolates of Fusarium spp. and to determine genetic relationships among formae speciales. Pathogenicity tests performed on dry beans (Phaseolus vulgaris) and soybeans (Glycine max) with 17 isolates of Fusarium solani did not demonstrate host specificity. Amplified Ribosomal DNA Restriction Analysis (ARDRA) was used to analyze the ITS1 - 5,8S rDNA - ITS2 region, amplified with primers ITS4 and ITS5. The amplified products were digested with the restriction enzymes Hae III and Msp I. Banding patterns generated by the enzyme Hae III enabled the differentiation of three groups within $F$. solani, one specific for isolates of $F$. solani $\mathrm{f}$. sp. phaseoli and the other two for $F$. solani f. sp. glycines. The ARDRA technique, using the enzyme Hae III, is a promising marker to differentiate the formae speciales phaseoli from glycines within the $F$. solani complex.
Fusarium solani (Mart.) Sacc. é um fungo do solo com ampla gama de hospedeiros que apresenta variação em sua morfologia, fisiologia e patogenicidade. A tradicional classificação e identificação de espécies no gênero Fusarium é baseada em características morfológicas como: morfologia da colônia de cultura monospórica de isolados em meios de cultura específicos, pigmentação e taxa de crescimento, especificidade de hospedeiros e perfil de metabólitos secundários (Thrane, 1990). Devido à plasticidade e variações de características fenotípicas no gênero Fusarium, a taxonomia baseada somente em conceitos morfológicos não é confiável, especialmente nas seções Martiella e Ventricosum (Snyder \& Hansen, 1953). Ocasionalmente, alguns isolados são considerados "intermediários", dificultando a separação entre espécies. No gênero Fusarium, há uma série de variações

*Bolsista do CNPq nas características morfológicas e patogênicas, resultando em uma classificação complexa dividida em seções, formae speciales e raças.

O conceito forma specialis foi ampliado por Snyder \& Hansen (1953) para reconhecer isolados patogênicos que foram morfologicamente semelhantes a isolados saprofíticos de mesma espécie, mas que diferenciam em sua habilidade para parasitar hospedeiros específicos. Estes isolados patogênicos estão classificados dentro de mais de 120 formae speciales e raças (Armstrong \& Armstrong, 1981). Entre estes, F. solani (Mart.) Sacc. f. sp. phaseoli (Burkholder) Snyder \& Hansen causa grandes danos na cultura do feijoeiro (Phaseolus vulgaris L.), onde já foram constatadas reduções de até $86 \%$ na produção, comprometendo a planta em situações de reduzido crescimento radicular devido à seca ou encharcamento. Ainda neste complexo inclui-se a síndrome da morte súbita da soja [Glycine max (L.) Merril], causada 
por F. solani (App. \& Wollenw.) Snyder \& Hans f. sp. glycines. Os sintomas são o apodrecimento das raízes secundárias da planta em solo úmido, necrose da base da planta e clorose interneval das folhas. A doença tem sido encontrada nas principais regiões produtoras de sementes do Sul e das regiões altas dos cerrados, podendo exterminar até $100 \%$ da plantação (Ferreira et. al., 1981; Gazzoni, et. al., 1995). Além destas culturas, existe ainda uma gama de hospedeiros de $F$. solani o que resultou na subdivisão da espécie em dez grupos subespecíficos. Na realidade, a especificidade de hospedeiro ocorre, mas não para todas as formae speciales (Armstrong \& Armstrong, 1981). Para algumas formae speciales, a classe de hospedeiros é ampla. Por esta razão, a sistemática molecular é uma ferramenta que oferece considerável segurança no estabelecimento de um sistema de classificação para fungos com base nas relações filogenéticas. A elucidação da taxonomia em $F$. solani, assim como dos agentes causais da podridão radicular e morte súbita, respectivamente, $F$. solani f. sp. phaseoli e $F$. solani f. sp. glycines, contribuiria para a definição das estratégias no controle destas doenças.

Diferentes técnicas têm sido utilizadas a fim de estudar a variabilidade genética em Fusarium spp. e identificar marcadores em nível de formae speciales e raças. Entre as técnicas utilizadas, o uso de marcadores RAPD (Random Amplified Polymorphic DNA) é utilizado como diagnóstico para a identificação de isolados de $F$. solani f. sp. glycines e F. solani f. sp. phaseoli (Achenbach et. al., 1996). Por outro lado, a técnica de RFLP (Restriction Fragment Length Polymorphism) foi utilizada para a determinação de grupos genéticos e sua relação com patogenicidade (Manicom et al., 1990). A unidade de DNA ribossomal (rDNA) nuclear consiste de uma série repetitiva (tandem) de três regiões gênicas (18S, 5.8S e 28S) e duas regiões espaçadoras intergênicas (ITS e IGS). Recentemente, a análise destas regiões espaçadoras do rDNA e estudos comparativos de seqüências de nucleotídeos de genes do rDNA, através da técnica ARDRA (Amplified Ribosomal DNA Restriction Analysis) têm sido utilizados. O valor deste método está na sua rapidez e habilidade para avaliar diferenças entre grupos filogenéticos, efetuando análises em vários níveis de classificação, inclusive em estudos de evolução, gerando novos marcadores para estudos de genética de populações (Jorgensen $\&$ Cluster, 1989).

Análise da região ITS foi efetuada em $F$. solani visando a reconstrução filogenética (O'Donnel \& Gray, 1995). Estudos de populações evidenciaram diversidade genética existente dentro da espécie de F. solani associada à batata (Solanun tuberosum L.) (Miller et al., 1999). Em Fusarium oxysporum, tem-se caracterizado, através de DNA mitocondrial, a diversidade entre isolados patogênicos com o objetivo de determinar relações genéticas entre formae speciales (Kim et al., 1993).

Este trabalho relata a análise da região ITS do rDNA através da técnica ARDRA para relacionar geneticamente isolados de $F$. solani f. sp. phaseoli e $F$. solani f. sp. glycines patogênicos ao feijão e/ou à soja.
Testes de patogenicidade foram efetuados previamente, através de inoculações cruzadas, com 11 isolados de $F$. solani f. sp. phaseoli e seis isolados de $F$. solani f. sp. glycines coletados do feijoeiro e soja, respectivamente, em várias localidades: Goiânia-GO, Acreúna-GO, Paranapanema-SP, Taquarituba-SP, Silvânia-GO e Londrina-PR (Tabela 1) (Oliveira \& Costa, 1999).

Para a extração de DNA, os isolados fúngicos foram cultivados em meio de cultura BDA e incubados a $27^{\circ} \mathrm{C}$ por sete dias. Discos de BDA contendo o micélio do fungo foram inoculados em $60 \mathrm{ml}$ de meio líquido extrato de levedura (10 $\mathrm{g}$ de extrato de levedura, $10 \mathrm{~g}$ de dextrose, $10^{-1} \mathrm{M}$ de ampicilina, $11 \mathrm{de} \mathrm{H}_{2} 0$ destilada), incubados a $27^{\circ} \mathrm{C}$, agitados a $120 \mathrm{rpm}$ durante sete dias. O micélio foi lavado em água destilada estéril, coletado por filtração a vácuo e liofilizado. A extração do DNA foi efetuada pelo método CTAB (cetiltrimetil brometo de amônio) (Zolan \& Pukilla, 1986). Efetuada a extração, quantificou-se o DNA em fluorômetro, procedendo-se as diluições para a concentração final de 10 $\mathrm{ng} / \mu 1$. Para a amplificação, foram utilizados os primers ITS5 ('5GGAAGTAAAAGTCGTAACAA 3') e ITS4 ('5 TCCTCC GCTTATTGATATGC 3') (Escola Paulista de Medicina, São Paulo) (White et al., 1990). Cada reação de amplificação de $25 \mu \mathrm{l}$ foi composta de 2,5 ng de DNA genômico; $13 \mu \mathrm{l}$ de água estéril; $10 \mathrm{mM}$ de Tris- $\mathrm{HCl} ; 2 \mathrm{mM}$ de $\mathrm{MgCl}_{2} ; 0,1 \mathrm{mM}$ de dNTP's; $1.25 \mathrm{U}$ de Taq DNA polimerase; $0,4 \mu \mathrm{M}$ de cada primer. As reações de amplificação foram realizadas em termociclador PTC 100 (MJ Research). Os ciclos de amplificação constituíram-se de uma etapa de desnaturação a $95^{\circ} \mathrm{C}$ por $4 \mathrm{~min}$, uma etapa de anelamento a $55^{\circ} \mathrm{C}$ por 1 min e uma etapa de extensão a $72^{\circ} \mathrm{C}$ por 2 min. Depois de 40 ciclos, foi efetuada uma última etapa de extensão a $72^{\circ} \mathrm{C}$ por $5 \mathrm{~min}$. De um total de $25 \mu \mathrm{l}$ do produto amplificado (em torno de $600 \mathrm{pb}$ ), $5 \mu \mathrm{l}$ foram digeridos utilizando-se $10 \mathrm{U}$ das enzimas de restrição Hae III e Msp I (Pharmacia Biotech, Uppsala, Sweden) diluídas em 1,5 $\mu \mathrm{l}$ de tampão e $8 \mu \mathrm{l}$ de água estéril destilada. Os produtos de digestão foram separados em gel de agarose a $1,4 \%$ contendo $0,5 \mu \mathrm{g} / \mathrm{ml}$ de brometo de etídeo, imerso em tampão TBE (Tris Borato 90,0 $\mathrm{mM}$, EDTA $1,0 \mathrm{mM}, \mathrm{pH} 8,0$ ) a $80 \mathrm{~V}$. O tamanho do produto amplificado foi estimado pela comparação com um marcador molecular de 100 pb (Gibco-BRL, Gaithersburg, MD, USA). As bandas de DNA foram visualizadas sob luz ultravioleta e fotografadas com o sistema de fotodocumentação Eagle Eye II (Stratagene).

Os resultados do teste de patogenicidade efetuando-se inoculação cruzada através do método de corte de raízes estão demonstrados na Tabela 1. Todos os isolados identificados como $F$. solani f. sp. glycines foram patogênicos ao feijoeiro. Dos isolados de $F$. solani f. sp. phaseoli, apenas três foram patogênicos apenas à cultura do feijoeiro, os demais isolados, foram patogênicos também à soja. Este resultado está de acordo com Armstrong \& Armstrong (1981), segundo os quais a especificidade de hospedeiro não ocorre para todas as formae speciales, não tendo sido aplicado para forma especialis de Fusarium spp. (apenas gênero) (Tosa, 1992). Estes mesmos 
Análise de restrição de DNA ribossomal amplificado (ARDRA) pode diferenciar...

TABELA 1 - Patogenicidade,forma specialis, procedência e grupo ARDRA/região ITS de isolados de Fusarium solani patogênicos ao feijoeiro (Phaseolus vulgaris) e/ou a soja (Glycine max)

\begin{tabular}{|c|c|c|c|c|c|c|}
\hline \multirow{2}{*}{ Isolado } & \multirow{2}{*}{ Origem } & \multirow{2}{*}{ Forma specialis } & \multirow{2}{*}{ Procedência } & \multicolumn{2}{|c|}{ Patogenicidade } & \multirow{2}{*}{$\begin{array}{c}\text { Grupo ARDRA } \\
\text { região ITS/Hae III }\end{array}$} \\
\hline & & & & Feijão & Soja & \\
\hline F01 & Feijão & phaseoli & Goiânia-GO & + & + & I \\
\hline F03 & Feijão & phaseoli & Acreúna-GO & + & + & I \\
\hline F14 & Feijão & phaseoli & Silvânia-GO & + & - & I \\
\hline F20 & Soja & glycines & Silvânia-GO & + & + & IIB \\
\hline F24 & Feijão & phaseoli & Unaí-MG & + & + & I \\
\hline F26 & Feijão & phaseoli & Unaí-MG & + & - & I \\
\hline F31 & Soja & glycines & Unaí-MG & + & + & IIA \\
\hline F33 & Feijão & phaseoli & $\mathrm{St}^{\circ}$ Antônio de GO & + & + & I \\
\hline F34 & Feijão & phaseoli & $\mathrm{St}^{\mathrm{o}}$ Antônio de GO & + & + & I \\
\hline F36 & Feijão & phaseoli & $\mathrm{St}^{\mathrm{o}}$ Antônio de GO & + & - & I \\
\hline F39 & Feijão & phaseoli & Silvânia-GO & + & + & I \\
\hline F40 & Feijão & phaseoli & Silvânia-GO & + & + & I \\
\hline F41 & Soja & glycines & Paranapanema-SP & + & + & IIA \\
\hline F42 & Soja & phaseoli & Taquarituba-SP & + & + & I \\
\hline F43 & Soja & glycines & Silvânia-GO & + & + & IIA \\
\hline F44 & Soja & glycines & Barreiras-BA & + & + & IIA \\
\hline F45 & Soja & glycines & Londrina-PR & + & + & IIA \\
\hline
\end{tabular}

(+)patogênico.

(-) não patogênico.

autores (Armstrong \& Armstrong, 1981) verificaram que isolados de F. oxysporum f. sp. raphani Ken. \& Snyd. e $F$. oxysporum f. sp. mathioli Snyd. \& Hans. e raças de F. oxysporum f. sp. conglutinans (Wholl.) Snyd \& Hans, são igualmente patogênicos ao repolho (Brassica oleraceae L.) e rabanete (Raphanus sativus L.).

Neste trabalho, os produtos gerados pela amplificação da região ITS e digestão pelas enzimas Hae III e Msp I não permitiram diferenciar os isolados que foram patogênicos à soja ou ao feijoeiro dos que foram patogênicos a ambas as culturas. Entretanto, a digestão dos produtos com Hae III, permitiram diferenciar $F$. solani f. sp. glycines de $F$. solani $\mathrm{f}$. sp. phaseoli (Figura 1) formando três grupos distintos. O grupo I mostrou-se homogêneo e constituído exclusivamente dos 11 isolados identificados como $F$. solani f. sp. phaseoli, com $100 \%$ de similaridade. Contudo, em $F$. solani f. sp glycines, revelou-se a existência de dois grupos, sendo cinco isolados inclusos no grupo IIA e um único isolado representando o grupo IIB (Tabela 1). Contrastando com estes resultados, O'Donnel \& Gray (1995) demonstraram, baseados no seqüenciamento e análise de RFLP da região ITS e parte da subunidade de $28 \mathrm{~S}$ do rDNA, que isolados que causam a morte súbita da soja podiam ser inclusos na forma specialis phaseoli. Entretanto, como este grupo também inclui isolados que não causam a doença, estes isolados que causam a morte súbita, devem representar uma população distinta dentro desta

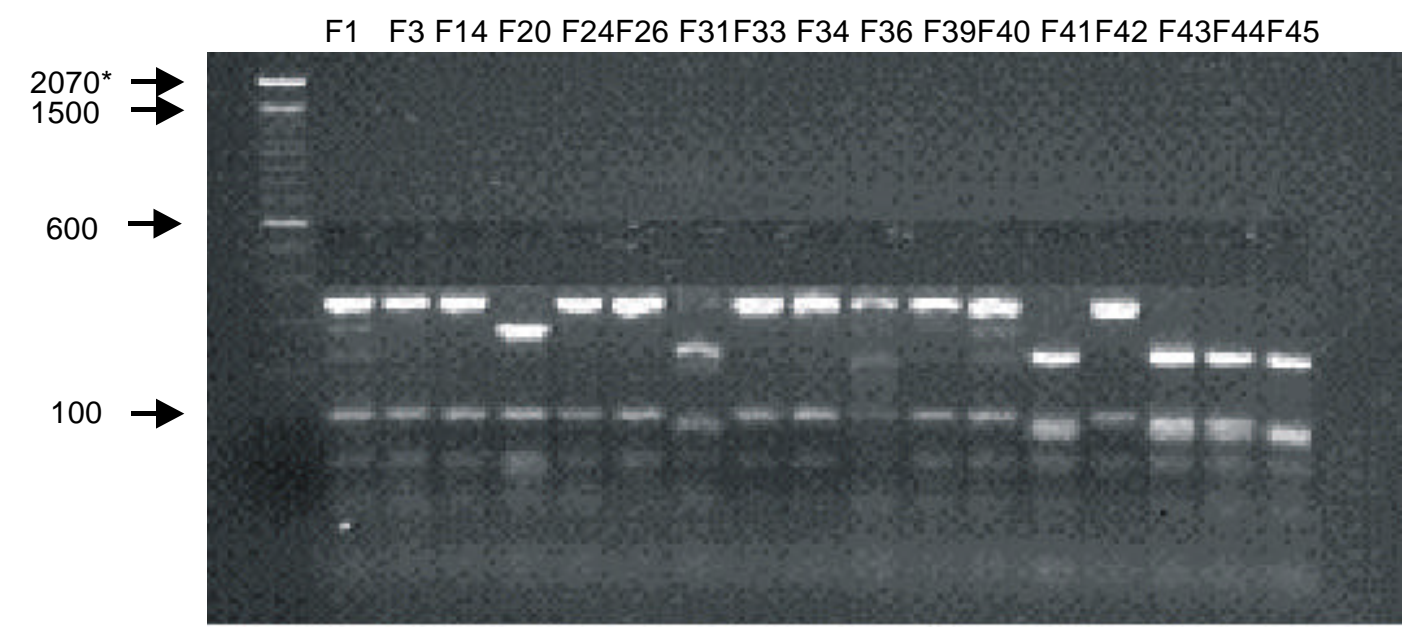

FIG. 1 - Produtos amplificados da região ITS-rDNA e digeridos com a enzima de restrição

Hae III de isolados de Fusarium solani f. sp. phaseoli e F. solani f. sp. glycines.

*Tamanho dos fragmentos em pares de bases (marcador $100 \mathrm{pb}$ ) 
forma specialis (O’Donnell \& Gray, 1995). Achenbach et. al. (1996) demonstraram a aplicabilidade de RAPD para diferenciar isolados de $F$. solani que causam a morte súbita dos isolados de $F$. solani que não causam sintomas foliares, típicos da doença, inclusive $F$. solani f. sp. phaseoli. Este trabalho, reportou o uso da técnica ARDRA como um marcador potencial para identificação de isolados, diferenciando $F$. solani f.sp. phaseoli de $F$. solani f. sp. glycines. A região ITS amplificada digerida pela enzima de restrição Hae III, nestes resultados preliminares, mostrou-se um marcador molecular eficiente, sendo uma técnica adicional de estudo para a complexa classificação taxonômica de Fusarium spp, e sobretudo poder elucidar controvérsias quanto à classificação dentro de forma specialis. Portanto, os marcadores moleculares provam ter tanta importância quanto os métodos baseados na morfologia e fisiologia, ampliando o nível de esclarecimentos na identidade e variabilidade do patógeno.

\section{AGRADECIMENTO}

Os autores agradecem pelo suporte financeiro do $\mathrm{CNPq}$ na realização deste trabalho.

\section{REFERÊNCIAS BIBLIOGRÁFICAS}

ACHENBACH, A.L., PATRICK, J. \& GRAY, L. Use of RAPD markers as diagnostic tool for the identification of Fusarium solani isolates that cause soybean sudden death syndrome. Plant Disease: 80:1228-1232. 1996.

ARMSTRONG, G.M. \& ARMSTRONG, J.K. Formae speciales and races of Fusarium oxysporum causing wilt diseases. In: Nelson, P.E., Toussoun, T.A. \& Cook, R.J. (Eds.). Fusarium: Disease, Biology, and Taxonomy. University Park. Pennsylvania State University Press. 1981. pp.391-399.

FERREIRA, L.P., LEHMAN, P.S. \& ALMEIDA, A.M.R. Moléstias e seu controle. In: Miyazaka, S. \& Medina, J.C. (Eds). A soja no Brasil. Campinas, SP, Brasil, Fundação Cargill. 1981. pp. 603-627.

GAZZONI, D.L. YORINORI, J.T. Manual de identificação de pragas e doenças da soja. Brasília: EMBRAPA - SPI, 1995.

JORGENSEN, R.A. \& CLUSTER, P.D. Modes and temps in the evolution of nuclear ribossomal DNA: new characters for evolutionary studies and new markers for genetic and population studies. Annual Missouri Botanical Garden 75:1238-1247. 1989.

KIM, D.H., MARTYN, R.D. \& MAGILL, C.W. Mitochondrial DNA (mtDNA) - Relatedness among formae speciales of Fusarium oxysporum in the Cucurbitaceae. Phythopathology 83:91-97. 1993.

MANICOM, B.Q., BAR-JOSEPH, M., KOTZE, J.M. \& BECKER, M.M. A restriction fragment length polymorphism probe relating vegetative compatibility groups and pathogenicity in Fusarium oxysporum f. sp. dianthi. Phytopathology 80:336339. 1990.

MILLER, R.N.G., QUEZADO-SOARES, A.M. \& LOPES, C.A. Molecular comparison of Fusarium populations causing eumartii wilt and dry rot of potato in Brazil. Fitopatologia Brasileira 24:149-155. 1999.

O'DONNEL, K. \& GRAY, E.L. Phylogenetic relationships of the soybean sudden death syndrome pathogen Fusarium solani f. sp. phaseoli inferred from rDNA sequence data and PCR primers for ITS identification. Molecular Plant-Microbe Interactions 8:709-716. 1995.

OLIVEIRA, V. C. de, COSTA, J.L. da S. Patogenicidade de formae specialis de Fusarium solani no feijão e na soja. Resumos, XXXII Congresso Brasileiro de Fitopatologia, Curitiba, PR. 1999. p.330.

SNYDER, W.C. \& HANSEN, H.N. Species concept, genetics, and pathogenicity in Hypomyces solani. Phytopathology 44:338342. 1953.

THRANE, U. Grouping Fusarium section Discolor isolates by statistical analysis of quantitative high performance liquid chromatographic data on secondary metabolite production. Journal Microbiologic Methods 12:23-39. 1990.

TOSA, Y.A. model for the evolution of formae speciales and races. Phytopathology 82:728-730. 1992.

ZOLAN, M.E. \& PUKILLA. P.J. Inheritance of DNA methylation in Coprinus cinerus. Molecular and Cellular Biology 6:195200. 1986.

WHITE, T.J., BRUNS, T.D., LEE, S. \& TAYLOR, J.W. Amplification and sequencing of fungal ribosomal RNA genes for phylogenetics. In: Innis, M.A., Gelfand, D.H., Sninsky, J.J., White, T.J. (Eds.). PCR Protocols: A Guide to Methods and Applications. San Diego. Academic Press, Inc. 1990. pp.315322. 